\title{
2-years effect on the soil nutrient supply after wastewater irrigation
}

\author{
Ágnes KUN - Csaba BOZÁN
}

National Agricultural Research and Innovation Centre (NAIK), Research Institution of Irrigation and Water Management (ÖVKI), H-5540 Szarvas, Anna-liget str. 35., Hungary; E-mail: kun.agnes@ovki.naik.hu; csaba.bozan@ovki.naik.hu

Keywords: nitrogen, phosphorous, potassium, lysimeter experiment

\section{Introduction}

Renewed interest in the reuse of wastewater is due to a combination of factors such as water scarcity, water supply demands, prolonged drought, climate variability, laws preventing direct discharge of wastewater into surface waters and the need to conserve freshwater (Ganjegunte et al. 2018, Roccaro and Verlicchi 2018). According to Abd-Elwahed (2018) the long-term application of wastewater offered water, nutrients and total organic matter to the soils but to avoid unwanted harmful effects from the wastewater applied to soil, regular assessment of soil quality is crucial. Aim of our study was to determine the impacts of the irrigated wastewater (originated from an intensive catfish farm with high nutrient and salt content due to the technology and geothermal origin) on the soil nutrient supply (NPK).

\section{Materials and methods}

The experiment was set up in Szarvas, Hungary, NAIK ÖVKI Lysimeter Station. For irrigation, in order to reduce the negative effects of geothermal origin for soil, wastewater of a fish farm was used in three treatments: untreated wastewater (UW), wastewater with calcium-sulphate amendment (WA), and diluted wastewater with amendment (DWA). Wastewater had high inorganic $\mathrm{N}$ content (Table 1). Irrigation water amount was 335 $\mathrm{mm}$ and $575 \mathrm{~mm}$ in 2016 and 2017, respectively. Control treatment was non-irrigated (RF as rainfed, in $2016189.5 \mathrm{~mm}$ and Körös River (KR) water irrigated in 2017). The experiment was conducted in 16 lysimeters $\left(1 \mathrm{~m}^{3}\right)$, each treatment with 4 replications. Irrigated plants were sorghum (2016) and rice (2017). The soil samples $\left(\sum 128\right)$ were collected before and after the irrigation periods. All water and soil analyses were made by the relevant Hungarian standards. The statistical calculation was performed in SPSS 22.0 Statistics Software. Paired Sample T-test was used to determine the significant changes in the nutrient concentrations between treatments.

Table 1: Chemical composition of the different wastewaters in the experiment

\begin{tabular}{|l|c|c|c|c|}
\hline & UW & WA & DWA & KR \\
\hline Ammonium-N $\left(\mathrm{mg} / \mathrm{dm}^{3}\right)$ & 24.4 & 24.4 & 10.8 & 0.37 \\
\hline Total phosphorous $\left(\mathrm{mg} / \mathrm{dm}^{3}\right)$ & 2.16 & 1.82 & 0.918 & 0.15 \\
\hline Potassium $\left(\mathrm{mg} / \mathrm{dm}^{3}\right)$ & 6.25 & 6.34 & 5.40 & 3.71 \\
\hline
\end{tabular}

\section{Results and discussion}

According to our results in 2016 the $\mathrm{N}$ content of the soil was higher after the irrigation period in all treatments. In case of UW and WA treatment the differences between the concentrations are significant (Table 2) due to the ammonium-N concentration of the irrigation water. In 2017, the highest $\mathrm{N}$ contents were measured again in the same treatments. Decrease of the soil N in 2017 could be because of more precipitation and rainwater amount which could leach the nitrate or more plant uptake. The phosphorous 
content of the soil did not show any alteration due to the wastewater irrigation excepting in 2016 in UW treatment. The available potassium level also did not change due to the wastewater treatments but the increase occurred because of natural soil formation.

Table 2: Nutrient supply of the soil $(0-90 \mathrm{~cm})$ in the wastewater irrigation experiment in 2016 and 2017

\begin{tabular}{|l|l|l|l|l|}
\hline Nitrogen mean (mg/kg) & $\mathbf{2 0 1 6}$ spring & $\mathbf{2 0 1 6}$ autumn & $\mathbf{2 0 1 7}$ spring & $\mathbf{2 0 1 7}$ autumn \\
\hline RF(irrigated KR in 2017) & 6.80 & 10.54 & 11.03 & $5.31^{* *}$ \\
\hline UW & 6.73 & $14.12^{* *}$ & 12.40 & 9.77 \\
\hline WA & 6.72 & $12.50^{* *}$ & 11.62 & 10.02 \\
\hline DWA & 7.07 & 7.99 & 10.62 & $5.89^{* *}$ \\
\hline Phosphorous mean (mg/kg) & $\mathbf{2 0 1 6}$ spring & $\mathbf{2 0 1 6}$ autumn & $\mathbf{2 0 1 7}$ spring & $\mathbf{2 0 1 7}$ autumn \\
\hline RF (irrigated KR in 2017) & 638 & 646 & 729 & 638 \\
\hline UW & 372 & $467^{*}$ & 381 & 385 \\
\hline WA & 534 & 653 & 540 & 414 \\
\hline DWA & 540 & 680 & 648 & $452^{*}$ \\
\hline Potassium mean (mg/kg) & $\mathbf{2 0 1 6}$ spring & $\mathbf{2 0 1 6}$ autumn & $\mathbf{2 0 1 7}$ spring & $\mathbf{2 0 1 7}$ autumn \\
\hline RF (irrigated KR in 2017) & 343 & $396^{*}$ & 372 & $467^{* * *}$ \\
\hline UW & 328 & $394^{* * *}$ & 341 & $439^{* *}$ \\
\hline WA & 328 & $390^{* *}$ & 349 & $446^{* *}$ \\
\hline DWA & 337 & $386^{* *}$ & 354 & $429^{* * *}$ \\
\hline
\end{tabular}

Note: Nitrogen: $\mathrm{KCl}-\mathrm{NO}_{2}^{-}+\mathrm{NO}_{3}^{-}-\mathrm{N}$, Phosphorous: $\mathrm{AL}-\mathrm{P}_{2} \mathrm{O}_{5}$, Potassium: $\mathrm{AL}-\mathrm{K}_{2} \mathrm{O}$.

$(*: p<0.05, * *: p<0.01, * * *: p<0.001, n=8)$

\section{Conclusions}

Overall, the applied wastewater had been suitable to enhance available $\mathrm{N}$ level of the soil. In case of $\mathrm{P}$ and $\mathrm{K}$ the original soil supplies were abundant - this type of wastewater could not enhance it. Increasing available potassium level is assumed to occur because of the natural mineralization of mica clay minerals. In the future, further investigation is needed to analyze the impact of the wastewater treatment on the nitrate leaching and plant nutrient uptake for this the plant analyzes and the chemical analyzes of the leaching water in progress.

\section{Acknowledgement}

The Ministry of Agriculture (OD001 project) funded our work.

\section{References}

Abd-Elwahed M. (2018): Influence of long-term wastewater irrigation on soil quality and its spatial distribution. Annals of Agricultural Sciences. (In Press) https://doi.org/10.1016/j.aoas.2018.11.004

Ganjegunte G., Ulery A., Niu G., Wu Y. (2018): Organic carbon, nutrient, and salt dynamics in saline soil and switchgrass (Panicum virgatum L.) irrigated with treated municipal wastewater. Land Degradation and Development. 29/1. 80-90. DOI: 10.1002/1dr.2841

Roccaro P. and Verlicchi P. (2018): Wastewater and reuse. Current Opinion in Environmental Science \& Health. 2. 61-63. https://doi.org/10.1016/j.coesh.2018.03.008 